NASA/TM-1999-107436

\title{
Probabilistic Analysis of Aircraft Gas Turbine Disk Life and Reliability
}

Matthew E. Melis and Erwin V. Zaretsky

Glenn Research Center, Cleveland, Ohio

Richard August

NYMA, Inc., Brook Park, Ohio

National Aeronautics and

Space Administration

Glenn Research Center 
Available from

NASA Center for Aerospace Information

7121 Standard Drive

Hanover, MD 21076

Price Code: A03
National Technical Information Service 5285 Port Royal Road Springfield, VA 22100

Price Code: A03 


\title{
PROBABILISTIC ANALYSIS OF AIRCRAFT GAS TURBINE DISK LIFE AND RELIABILITY
}

\author{
Matthew E. Melis and Erwin V. Zaretsky \\ National Aeronautics and Space Administration \\ Glenn Research Center \\ Cleveland, Ohio 44135 \\ and \\ Richard August \\ NYMA, Inc. \\ Brook Park, Ohio 44142
}

\begin{abstract}
Two series of low-cycle-fatigue (LCF) test data for two different groups of aircraft gas turbine engine compressor disk geometries were reanalyzed and compared by using Weibull statistics. Both groups of disks were manufactured from titanium (Ti-6Al-4V) alloy. A probabilistic computer code called Probable Cause was used to predict disk life and reliability. A material-life factor $A$ was determined for the titanium ( $\mathrm{Ti}-6 \mathrm{Al}-4 \mathrm{~V}$ ) alloy by using fatigue disk data and was applied to predict disk life as a function of speed. A comparison was made with results from the currently used life prediction method, which is based on crack growth rate. Applying an endurance limit to the computer code did not significantly affect the predicted lives under engine operating conditions. Failure location predictions correlated with experimentally observed failure locations in the LCF tests. A reasonable correlation was obtained between the disk lives predicted by using the Probable Cause code and those predicted by using a modified crack growth method. Both methods slightly overpredicted life for one disk group and significantly underpredicted it for the other.
\end{abstract}

\section{NOMENCLATURE}

A material-life factor

c stress-life exponent

e Weibull slope

$F$ probability of failure, fraction or percent

$h$ exponent 
$K_{T} \quad$ constant, $\operatorname{deg} \mathrm{C}(\operatorname{deg} \mathrm{F})$

$L \quad$ life, number of stress cycles or hr

$L_{0.1} \quad 0.1$-percent life, or life at which 99.9 percent of a population survives, number of stress cycles or hr

$L_{1} \quad 1$-percent life, or life at which 99 percent of a population survives, number of stress cycles or hr

$L_{10} \quad$ 10-percent life, or life at which 90 percent of a population survives, number of stress cycles or hr

$L_{50} \quad 50$-percent life, or life at which 50 percent of a population survives, number of stress cycles or hr

$L_{\beta} \quad$ characteristic life, or life at which 63.2 percent of a population fails, number of stress cycles or hr

$m \quad$ Weibull slope

$N \quad$ life, number of stress cycles

n number of components, elemental volumes, or bolt holes

$S \quad$ probability of survival, fraction or percent

$T \quad$ steady-state temperature, ${ }^{\circ} \mathrm{C}\left({ }^{\circ} \mathrm{F}\right)$

$\Delta T \quad$ thermal gradient, deg C (deg F)

$V \quad$ stressed volume, $\mathrm{m}^{3}\left(\right.$ in..$\left.^{3}\right)$

$X \quad$ load, time, or stress

$X_{1}, X_{2}$ fractional time at load and/or speed 
$Z$ depth to maximum critical shear stress, $m$ (in.)

$\begin{array}{ll}\sigma & \text { stress or strength, } \mathrm{N} / \mathrm{m}^{2}(\mathrm{psi}) \\ \sigma_{u} & \text { location parameter, } \mathrm{N} / \mathrm{m}^{2}(\mathrm{psi}) \\ \tau & \quad \text { critical shear stress, } \mathrm{N} / \mathrm{m}^{2} \text { (psi) } \\ \tau_{45} & \text { maximum shear stress, } \mathrm{N} / \mathrm{m}^{2} \text { (psi) }\end{array}$

Subscripts

$i \quad$ ith component or stressed volume

$n \quad$ number of components or elemental volumes

ref reference point, stress, volume, or life

sys system or component probability of survival or life

$v \quad$ related to stressed volume

$\beta \quad$ designates characteristic life or stress

\section{INTRODUCTION}

According to Coy, ${ }^{1}$ a simplistic approach to component life and reliability would be a completely deterministic one. That is, each component in the system would be subjected to the scrutiny of determining its calculated stress for an assumed load in service. The calculated stress would be compared with an allowable stress for an assumed material strength. The deterministic approach assumes that if the material strength is greater than the applied stress, the component will not fail (i.e., the life will be infinite). (Stress is compared with strength by using the appropriate failure criteria, e.g., maximum shear stress, strain energy, distortion energy, or fatigue.) The deterministic method assumes that full and certain knowledge exists for the service conditions and the material strength.

For most aerospace applications designing for infinite life with a zero probability of component failure would require structural size and weight that would not be compatible with aircraft and spacecraft flight. As a result it becomes prudent to design for finite life with an acceptable risk or 
probability of failure. Hence, a more reasonable assessment of component life and reliability for aerospace and, perhaps, nonaerospace applications is based on a probabilistic approach to design and analysis.

A. Palmgren ${ }^{2,3}$ in 1924 suggested a probabilistic approach to predicting the lives of machine components and, more specifically, rolling-element bearings. On the basis of his test results he suggested that an acceptable life be defined as that time at which 10 percent of a population of bearings will have failed or 90 percent will have survived. He also noted that there was an apparent size effect on life. That is, larger bearings with the same equivalent load as smaller bearings had shorter lives than the smaller bearings.

In $1939 \mathrm{~W}$. Weibull ${ }^{4-6}$ published two papers that describe a statistical approach to determining the strength of solids. Weibull postulated that the dispersion in material strength for a homogeneous group of test specimens can be expressed according to the following relation:

$$
\ln \ln \frac{1}{S}=e \ln \left[\frac{X}{X_{\beta}}\right]
$$

where $X=\sigma$ and $X_{\beta}=\sigma_{\beta}$ (see Appendix A).

Equation (1) relates the probability of survival $S$ and the fracture (or rupture) strength $\sigma$. When $\ln \ln (1 / S)$ is used as the ordinate and $\ln \sigma$ as the abscissa, fracture (and fatigue) data are assumed to plot as a straight line. The slope (tangent) of this line is referred to as the "Weibull slope" or "Weibull modulus" usually designated by the letter $e$ or $m$. The plot itself is referred to as a "Weibull plot."

By using a Weibull plot it becomes possible to estimate a cumulative distribution of an infinite population from an extremely small sample size. The Weibull slope is indicative of the dispersion of the data and its density (statistical) distribution. Weibull slopes of 1,2, and 3.57 are indicative of exponential, Raleigh, and normal (Gaussian) distributions, respectively. ${ }^{7}$

The scatter in the data is inversely proportional to the Weibull slope. That is, the lower the value of the Weibull slope, the larger the scatter in the data and vice versa. The Weibull slope is also liable to statistical variation depending on the sample size (data base) making up the distribution. ${ }^{8}$ The smaller the sample size, the greater the statistical variation in the slope.

Weibull $^{4,5}$ related the material strength with the volume of the material subjected to stress. If we imagine the solid to be divided in an arbitrary manner into $n$ volume elements, the probability of survival for the entire solid can be obtained by multiplying the individual survivabilities together as follows:

$$
S=S_{1} \cdot S_{2} \ldots S_{n}
$$

where the probability of failure $F$ is

$$
F=1-S
$$


Weibull ${ }^{4,5}$ further related the probability of survival $S$, the material strength $\sigma$, and the stressed volume $V$, according to the following relation:

$$
\ln \frac{1}{S}=\int_{V} f(X) d V
$$

where

$$
f(X)=\sigma^{e}
$$

For a given probability of survival $S$

$$
\sigma \sim\left[\frac{1}{V}\right]^{1 / e}
$$

From Eq. (6) for the same probability of survival the components with the larger stressed volume will have the lower strength (or shorter life). This principle was applied to successfully normalize rolling-element fatigue life by $\operatorname{Carter}^{9}$ and Zaretsky et al. ${ }^{10}$ This equation was also applied by Grisaffe ${ }^{11}$ in a Weibull analysis of the bond strength of plasma-sprayed alumina coatings on stainless steel. Grisaffe showed that the calculated mean bond shear strength decreased with increasing test area in accordance with Eq. (6).

In 1947, G. Lundberg and A. Palmgren ${ }^{12}$ applied Weibull analysis to the prediction of rollingelement bearing fatigue life. The Lundberg-Palmgren theory expressed $f(X)$ in Eq. (4) as

$$
f(X)=\frac{\tau^{c} N^{e}}{Z^{h}}
$$

where $\tau$ is the critical shear stress, $N$ is the number of stress cycles to failure, and $Z$ is the depth to the maximum critical shear stress in a concentrated (Hertzian) contact. From Eqs. (4) and (7)

$$
N \sim\left[\frac{1}{\tau}\right]^{c / e}\left[\frac{1}{V}\right]^{1 / e}\left[\frac{1}{Z}\right]^{h / e}
$$

From Lundberg and Palmgren ${ }^{12}$ (see Appendix B) the lives of individual stressed volumes at a given probability of survival are summarized as follows:

$$
\left[\frac{1}{N}\right]^{e}=\sum_{i=1}^{n}\left[\frac{1}{N_{i}}\right]^{e}
$$


Equations (1) to (4) and (7) to (9) are the basis for the international standards for rating rollingelement bearing life. ${ }^{13-15}$

In Lundberg and Palmgren ${ }^{12}$ the parameter $c / e$ is the stress-life exponent. This implies that the inverse relation of life with stress is a function of the life scatter or data dispersion. A search of the literature for a wide variety of materials would suggest that the stress-life exponent is independent of Weibull slope $e$. Also, from observation, and contrary to the Lundberg-Palmgren assumption, fatigue life appears to be independent of the depth to the maximum critical shear stress in a body. Hence, Zaretsky ${ }^{16}$ has modified the Lundberg-Palmgren theory where

$$
f(X)=\tau^{c e} N^{e}
$$

From Eqs. (4) and (10)

$$
N \sim\left[\frac{1}{\tau}\right]^{c}\left[\frac{1}{V}\right]^{1 / e}
$$

Zaretsky ${ }^{17}$ as well as Ioannides and Harris ${ }^{18}$ proposed a generalized Weibull-based methodology for structural life prediction that uses a discrete-stressed-volume approach. August and Zaretsky ${ }^{19}$ extended this methodology by developing a technique for predicting component life and survivability that is based on finite-element stress analysis. Holland et al. ${ }^{20}$ applied this method to predicting the fracture strength and life of a metal-matrix composite ring and used coupon data to determine the Weibull parameters for the material. Melis and Ogonek ${ }^{21}$ implemented this life prediction methodology through a computer code called Probable Cause.

The computer code Probable Cause has not been benchmarked and compared with a statistical data base for aircraft engine components. Such a data base does exist. Mahorter et al. ${ }^{22}$ reported lowcycle-fatigue (LCF) testing conducted by the Naval Air Development Center (NADC) and the Naval Air Propulsion Center (NAPC) and the resultant life data for two different groups of gas turbine engine compressor disks. The disks were each manufactured from a titanium (Ti-6Al-4V) alloy. They compared the results with analytical predictions by a crack growth method. Their conclusion was that their analytical predictions were not conservative.

In view of the aforementioned it became the objectives of the work reported herein: (1) to exercise the computer code Probable Cause to predict the life and reliability of the two groups of gas turbine engine compressor disks tested by the Navy; (2) to compare and benchmark the predicted and experimental results; (3) to determine a material-life factor for use in the computer code for a titanium (Ti-6Al-4V) alloy; and (4) to determine what effect, if any, the assumption of a material endurance limit may have on predicted disk life.

\section{COMPUTER CODE PROBABLE CAUSE}

The computer code Probable Cause is written in PATRAN command language (PCL) and is based on the computational method of August and Zaretsky. ${ }^{19}$ The component life and survivability are predicted by finite-element analysis. By establishing a reference life $L_{\text {ref }}$, a unit or gage volume $V_{\text {ref }}$, and a reference stress $\tau$ related to the reference life and gage volume, Eq. (11) can be rewritten substituting $L$ for $N$ as follows: 


$$
L=L_{\mathrm{ref}}\left[\frac{\tau_{\mathrm{ref}}}{\tau}\right]^{c}\left[\frac{V_{\mathrm{ref}}}{V}\right]^{1 / e}
$$

By replacing $X$ in Eq. (1) with $L$, the probability of survival $S$ and the life $L$ can be related to $S_{\text {ref }}$ and $L_{\text {ref }}$ as follows:

$$
S=S_{\mathrm{ref}}^{\left(L_{\mathrm{ref}} / L\right)^{e}}
$$

By using Eqs. (12) and (13) and critical shear stress results from a finite-element analysis, $L$ and $S$ values for each element are computed. Hence, the probability of survival for the entire analysis model can be obtained by using Eq. (2) to multiply the individual survivabilities.

These equations provide relative or normalized values for $L$ and $S$ in relation to reference values chosen from the selected element. Generally, reference values of 1.0 and 0.9 are assigned to the $L_{\text {ref }}$ and $S_{\text {ref }}$ variables, respectively, in the equations. These values imply a relative or normalized life of unity and a probability of survival of 90 percent for the reference element or volume $V_{\text {ref }}$. Maximum shear stress or Von Mises stress values are normally used because they are applicable to failure theory for ductile materials. A reference element or volume can be chosen at random. However, the authors have primarily used the element with the highest resultant stress as a reference point. The stress-life exponent $c$ and the Weibull slope $e$ are parameters specific to the material. August and Zaretsky ${ }^{19}$ have previously discussed the rationale for obtaining these values.

The computer code was embedded in a PATRAN finite-element code. The program operates on analysis results within the PATRAN data base. It stores the life and survivability predictions for each stressed volume (mesh element) as additional result files for postprocessing by using the standard PATRAN tools. ${ }^{21}$ The data output provides the system life and the probability of survival. In addition to the conventional stress contours for the component, contour plots are provided for probability of survival (or failure) and life.

\section{TURBINE DISKS}

\section{Specimens and Procedure}

Mahorter et al. ${ }^{22}$ studied two different groups of aircraft gas turbine engine compressor disks designated disks $\mathrm{A}$ and disks $\mathrm{B}$. The disks were manufactured from a titanium (Ti-6Al-4V) alloy. The material parameters for this alloy, taken from various published sources, are given in Table 1. Schematic drawings of these disks are shown in Fig. 1. Five unfailed disks of each type were randomly selected from those removed from engines at overhaul. The disk operating times are summarized in Table 2 . These failure data are the only such data reported and available in the open literature. Using them allowed us to exercise the Probable Cause code and to compare the results with actual components that had been run in aircraft engine service.

Data were not made available by Mahorter et al. ${ }^{22}$ as to the total number of unfailed disks of each type removed from service and their respective operating times, the number of disks that were removed from service because of crack initiation and their respective operating times, and the material processing and metallurgical characteristics of the titanium alloy used for each disk. Hence, 
we do not know the actual population size that each set of disks represents. Also not reported were the manufacturing process and engine operating temperature for each disk. These unreported variables can affect disk life and the accuracy of the statistical life results reported herein.

In the aircraft engine these disks operated at speeds between 11000 and $11800 \mathrm{rpm}$. The disks' in-flight operating temperatures were not reported. After removal at engine overhaul these disks were isothermally cyclic tested at a speed of $11200 \mathrm{rpm}$ in spin pits at the Naval Air Propulsion Center (NAPC) ${ }^{22}$ A spin pit test cycle is shown in Fig. 2. One cycle is equivalent to 1.45 flight hours for disks A and 1.54 flight hours for disks B. The equivalent stress cycles for engine operation and for the NAPC (spin pit) tests are given in Table 2. A failure is defined as the first occurring crack equal to or greater than $0.7938 \mathrm{~mm}\left(0.03125 \mathrm{in}\right.$.) no matter where in the disk it occurs. ${ }^{22}$ These data were analyzed by using the method of Johnson ${ }^{8}$ and two-parameter Weibull analysis because of the limited number of data points. Three-parameter Weibull analysis would estimate a running time below which no failure would be expected to occur ( 100 percent probability of survival). (See Appendix A.) The results of these analyses are shown in the Weibull plots of Fig. 3 and summarized in Table 2.

For aircraft engine applications and comparisons a probability of survival of 99.9 percent is used (i.e., the operating time exceeded by 99.9 percent of the components or the time at which 0.1 percent have failed). This time is designated as the $L_{0.1}$ life. According to Mahorter et al. ${ }^{22}$ at the $L_{0.1}$ life disk retirement policy recommends either the removal or reworking of the "used disk." From Eq. (1), where $X=L$, the $L_{0.1}$ life is calculated from the data of Fig. 3 according to the following:

$$
L_{0.1}=L_{\beta} \exp -\left[\frac{6.9073}{e}\right]
$$

\section{Stress Analysis and Life Prediction}

A NASTRAN linear static finite-element analysis (FEA) was used to predict the maximum shear stresses $\tau_{45}$ of the disks. The FEA model mesh of sections of disks A and B are shown in Fig. 4. Symmetry in the disks allowed for reduced model segments to be used for analysis. Hence, disk $A$ was analyzed as a $60^{\circ}$ segment and disk $B$ as a $30^{\circ}$ segment.

Both disks were analyzed for stress and probability of failure for two load conditions at 11200 $\mathrm{rpm}$. One condition related to disk operation in the engine under full compressor blade (rim) loading. The second condition related to the NAPC spin tests without compressor blade (rim) loading. These FEA maximum shear stress results for the disks are shown in Fig. 5. For these analyses the contact (Hertz) stresses between the bolt and the bolt hole and between the blade root and the blade slot were not considered.

For both disks a common gage or reference volume was chosen with a reference stress. Although this volume and stress can be chosen arbitrarily, it is most efficient for calculation purposes to select a gage volume having a high stress. For purposes of these calculations a reference volume of $2.264709 \times 10^{-10} \mathrm{~m}^{3}\left(1.3820105 \times 10^{-5} \mathrm{in.}^{3}\right)$ having a $\tau_{45}$ stress of $509.2 \mathrm{MPa}(73.846 \mathrm{ksi})$ was chosen.

A sensitivity analysis performed by Zaretsky et al. ${ }^{23}$ on a generic rotating disk showed that the $L_{10}$ life was insensitive to changes in Weibull slope $e$ greater than 2 and to stress-life exponents $c$ 
between 7 and 13. The results of these analyses are shown in Fig. 6. From these analyses and the data of Fig. 3 a Weibull slope of 2 was chosen for the current life analysis to represent the failure distribution of both disks. By using fatigue data from the Aerospace Materials Handbook ${ }^{24}$ we calculated a stress-life exponent of 9.2 for the titanium (Ti-6Al-4V) alloy and assumed it to represent that of the disk.

The results of these analyses showing the probability of failure and the failure location on each disk are shown in Fig. 7. This figure suggests that for both disks and at all load conditions the bolt holes have the highest probability of failure. All the failure locations reported by Mahorter et al. ${ }^{22}$ for both sets of disks were bolt hole cracks. According to Mahorter et al. ${ }^{22}$ turbine engine LCF experience has shown that the bolt holes are the primary location of engine disk failure.

\section{RESULTS AND DISCUSSION}

\section{Comparison of Lives}

By using the method of Zaretsky ${ }^{16.17 .19}$ and the computer code Probable Cause, ${ }^{21}$ a life analysis was undertaken of two different groups of aircraft gas turbine engine compressor disks for which there existed fatigue data. ${ }^{22}$ These disks were manufactured from titanium (Ti-6Al-4V) alloy. The normalized predicted lives are summarized in Table 3(a). The disks may have been operated under two load conditions. Life prediction for a disk under combined loading depends on the percentage of the total operating time at each load and the individual life attainable under that load. When using a linear damage (Palmgren-Langer-Miner) ${ }^{2.25 .26}$ rule, the predicted disk life under the combined load conditions is as follows:

$$
\frac{1}{L_{s y s}}=\frac{X_{1}}{L_{1}}+\frac{X_{2}}{L_{2}}
$$

Referring to Table 2, the time at each load condition was varied for both disks A and B. However, it can be reasonably assumed, for purposes of calculation, that for disks A the time share was 18 percent under engine load conditions and 82 percent under spin pit conditions and that for disks B the time share was 15 and 85 percent, respectively. The results of these combined load-cycle calculations are shown in Table 3. Comparing these results qualitatively would suggest that disks $\mathrm{A}$ would provide a life approximately 14 percent longer than that provided by disks B.

According to Mahorter et al. 22 "the test buildup for the compressor disks was essentially a subsection of the compressor complete with spacers and blade." It could therefore be reasonably assumed that the spin test loading approached or equaled the engine loading. As a result further comparisons were made for the loaded (engine) conditions. Under these conditions the lives of disks A would be expected to be 35 percent longer than those of disks $B$.

From Fig. 3 and Table 2 the $L_{0.1}$ and $L_{10}$ lives of disks B were longer than those of disks A, but the reverse was true for the $L_{50}$ life. Unfortunately, the number of data points for both disks $\mathrm{A}$ and B was not sufficient to provide statistical significance to the life differences, to the absolute life values, or to the failure distributions (Weibull slopes) shown in Fig. 3. 


\section{Effect of Endurance (Fatigue) Limit}

An endurance (fatigue) limit for a material suggests that where the stresses in the material are below this limit the life of that elemental volume will be infinite (i.e., the probability of survival is 100 percent). If the entire structure has its stresses below this value, the structure would not be anticipated to fail from fatigue. From the literature ${ }^{24}$ the estimated fatigue limit for the maximum shear stress $\tau_{45}$ for the titanium alloy used is $258.5 \mathrm{MPa}(37.5 \mathrm{ksi})$. This value is derived from tensile loading fatigue tests.

Referring back to the FEA stress analysis in Fig. 5, those elemental stressed volumes whose stresses are less than $258.5 \mathrm{MPa}(37.5 \mathrm{ksi})$ were assigned a survival probability of 100 percent. The disk lives were recalculated accordingly. These life results are summarized in Table 3 (b) for the two load conditions of each group of disks and were combined by using Eq. (15). For the unloaded conditions the fatigue limit can significantly affect life. However, for the loaded and combined conditions the assumption of a fatigue limit did not significantly alter the calculated lives summarized in Table $3(\mathrm{a})$.

\section{Reference Life and Material-Life Factor}

By using Eq. (12) the reference life $L_{\text {ref }}$ was normalized as one cycle for $V_{\text {ref }}=2.264709 \times 10^{-10} \mathrm{~m}^{3}\left(1.3820105 \times 10^{-5}\right.$ in..$\left.^{3}\right)$ and $\tau_{\text {ref }}=509.2 \mathrm{MPa}(73.846 \mathrm{ksi})$. In order to assign an absolute value to $L_{\text {ref }}$ to predict life, it is necessary to benchmark the normalized predicted lives in Table 3(a) with the experimental $L_{10}$ lives in Table 2. Since disks A resulted in the shortest experimental life, they were used to benchmark the analysis.

For combined loading of disks A

$$
\begin{gathered}
0.33147 L_{\text {ref }}=7900 \text { cycles } \\
L_{\text {ref }}=23833 \text { cycles }
\end{gathered}
$$

For the engine (loaded) condition of disks A

$$
\begin{gathered}
0.05968 L_{\text {Tef }}=7900 \text { cycles } \\
L_{\text {ref }}=132373 \text { cycles }
\end{gathered}
$$

A material-life factor $A$ for the titanium (Ti-6Al-4V) alloy can be defined and determined from Eq. (12) where

$$
A=L_{\text {ref }} V_{\text {ref }}^{1 / e} \tau_{\text {ref }}^{c}
$$

For $L_{\text {ref }}$ from Eq. $(16 \mathrm{~b}), e=2, c=9.2, V_{\text {ref }}=2.264709 \times 10^{-10} \mathrm{~m}^{3}\left(1.3820105 \times 10^{-5}\right.$ in. $\left.{ }^{3}\right)$, and $\tau_{\text {ref }}=509.2 \mathrm{MPa}(73.846 \mathrm{ksi})$ 


$$
\begin{aligned}
& A=2.527 \times 10^{80} \text { cycles } \cdot\left[\frac{\mathrm{N}^{9.2}}{\mathrm{~m}^{16.9}}\right] \\
& \text { (International units) } \\
& A=3.024 \times 10^{47} \text { cycles } \cdot\left[\frac{\mathrm{lb}^{9.2}}{\text { in. }^{16.9}}\right]
\end{aligned}
$$

(Customary units)

From Eq. (1) for a Weibull slope $e$ of 2 the $L_{0.1}$ life can be calculated as a function of the $L_{10}$ life as follows:

$$
L_{0.1}=0.07447 L_{10}
$$

By using the reference lives from Eqs. (16a) and (16b) and the computer code Probable Cause, the absolute predicted $L_{10}$ lives in number of cycles were calculated for disks A and B at four speeds. From the $L_{10}$ live the $L_{0.1}$ lives were calculated from Eq. (18) and converted into engine hours.

These results are summarized in Table 4 . The predicted $L_{0.1}$ lives from Table $4(\mathrm{~b})$ are plotted as a function of speed in Fig. 8 and compared with the experimental $L_{0.1}$ lives from Table 2. At the lower speeds disks B are predicted to have longer life than disks A. At the higher speeds the reverse is predicted. This crossover appears to occur at or about $11200 \mathrm{rpm}$. Had the Von Mises stress values been used for this analysis the resultant lives may have been altered from those predicted by using the maximum shear stress $\tau_{45}$.

\section{Thermal and Residual Stress Effects}

The analysis reported was undertaken only with those material data and operating conditions available in the open literature. Because the disk operating temperatures were not reported, ${ }^{22}$ we did not consider them. That is not to imply that temperature has no effect. The temperature and resulting temperature gradients in the disk have a two-fold effect. First, the fatigue life of a material generally decreases with temperature. Second, thermal gradients in the disk induce thermal stresses.

Zaretsky et al. ${ }^{23}$ present an expression for thermal effects (based on uniform, radial, linear temperature gradients) on disk relative life as follows:

$$
L \sim\left[\frac{K_{T}}{\Delta T}\right]^{0.52}
$$

where $\Delta T$ is the total radial temperature difference and $K_{T}$ is a constant equal to $0.56 \mathrm{deg} C$ when $\Delta T$ is in degree Celsius or $1 \mathrm{deg} F$ when $\Delta T$ is in degrees Fahrenheit and where $\Delta T$ is equal to or greater than $K_{T}$. Hence, if the temperature gradient in the disk is known, Eq. (19) can be used to adjust the life prediction up or down. 
The bulk operating disk temperature will also affect life. In general, compressor disk operating temperatures can approach or exceed $649^{\circ} \mathrm{C}\left(1200^{\circ} \mathrm{F}\right)$. There are no available data for the disk material showing the effect of bulk temperature on fatigue life.

Another variable not considered and for which information was not available was compressive residual stresses present in the disk material. These residual stresses could be present as the result of either heat treatment or shot peening. Accordingly, the compressive residual stresses can reduce the effective shear stresses and thus increase life. These data are also not available.

The effects of temperature, thermal stresses, and residual stresses on the accuracy of the life predictions and the determination of the material-life factor $A$ may or may not be significant to the work reported herein. Since for approximately 15 to 20 percent of the time the disks were run at elevated temperatures in the engine, the value of $A$ as it applies to ambient (room) temperature conditions may be too low. However, at elevated conditions the value of $A$ may be to high.

The effect of residual stresses may be relatively the same at both room temperature and elevated temperatures. Thermal stresses were not present at room temperature in the spin pit tests. At ambient (room) temperature the residual stresses will increase life relative to the same material without residual stresses.

\section{Crack Growth Life Prediction Method}

The currently used analytical life prediction method is based on material crack propagation rates at the highest stress point in the structure. The time for an initial flaw size to reach a defined length or size determines the mean or average life of the structure.

Mahorter et al. ${ }^{22}$ did not report what this initial flaw size was assumed to be but defined the initial crack length to failure as being equal to or greater than $0.7938 \mathrm{~mm}(0.03125 \mathrm{in}$.). The logic in choosing this crack length is that it is the smallest that can be detected by current state-of-the-art inspection techniques.

It is assumed that the density distribution about the log of the mean life prediction is normal (or Gaussian). Accordingly, a $3 \sigma$ deviation about the $\log$ of the mean life results in an $L_{0.1}(99.9$ percent probability of survival) life prediction.

For the compressor disk the bolt holes are the highly stressed area and are the location where Mahorter et al. ${ }^{22}$ assumed crack initiation to occur. They detected no cracks in the blade slot area of disks A. Mahorter et al. ${ }^{22}$ calculated disk life for only a single bolt hole location and did not consider multiple bolt hole locations. Their calculated $L_{0.1}$ lives are summarized in Table 5 . We modified the NAPC-predicted lives ${ }^{22}$ by using Eq. (9) to account for the entire number of bolt holes in each disk, where Eq. (9) (see Appendix B) can be written as follows:

$$
L_{\text {sys }}=\frac{L}{(n)^{1 / e}}
$$

and where $L$ is the NAPC-predicted life for disks with a single bolt hole, $n$ is the number of bolt holes, and $e$ is the Weibull slope of 2 . For disks $\mathrm{A}$ and $\mathrm{B}, n$ equal 12. The recalculated lives based on Eq. (20) for disks $A$ and $B$ are summarized in Table 5. Comparing the $L_{0.1}$ life predictions by the modified current method with those by the Zaretsky Probable Cause method shows a reasonably close correlation. Both methods slightly overpredicted life for disks $A$ and significantly underpredicted life for disks B. 


\section{SUMMARY OF RESULTS}

Two series of low-cycle-fatigue (LCF) test data for two different groups of aircraft gas turbine engine compressor disks were reanalyzed and compared by using Weibull statistics. Both groups of disks, designated disks A and disks B, were manufactured from a titanium (Ti-6Al-4V) alloy. Tests had been run by the U.S. Naval Air Propulsion Center (NAPC). A probabilistic computer code based on the methods of Zaretsky and called Probable Cause was used to predict disk life and reliability. Probable Cause, which is a method for estimating a component's design survivability and life, incorporates finite-element analysis and probabilistic material-life properties. The analysis was normalized to one set of disk data to obtain a material-life factor $A$ applicable to the titanium alloy. This material-life factor $A$ was used with the computer code to predict disk life as a function of speed. A comparison was made with a modified current life prediction method, which is based on crack growth rate. The following results were obtained:

1. A reasonable correlation was obtained between the disk lives predicted by using the computer code Probable Cause and those predicted by using a modified crack growth life prediction method. Both methods sightly overpredicted the life for disks A and significantly underpredicted life for disks B.

2. A material-life factor $A$ based on disk fatigue data was determined for the titanium (Ti-6Al$4 \mathrm{~V}$ ) alloy and applied to predict disk life as a function of speed. The value of $A$ for the titanium alloy was $2.527 \times 10^{80}$ cycles $\cdot \mathrm{N}^{9.2} / \mathrm{m}^{16.9}\left(3.024 \times 10^{47}\right.$ cycles $\left.\cdot \mathrm{Ib}^{9.2} / \mathrm{in} .^{16.9}\right)$.

3. The failure probability analysis for both disk groups predicted with reasonable engineering certainty the failure locations at the bolt holes of each disk. These locations correlated to those observed experimentally in the disk LCF tests.

4. Applying an endurance (fatigue) limit to the computer code Probable Cause did not significantly affect the predicted disk lives under engine operating conditions relative to when an endurance limit was not used in the analysis. 


\section{APPENDIX A-DERIVATION OF WEIBULL DISTRIBUTION FUNCTION}

According to Weibull ${ }^{6}$ any distribution function can be written as

$$
F(X)=1-\exp -[f(X)]
$$

where $F(X)$ is the probability of an event (failure) occurring. Conversely, from the above the probability of an event not occurring (survival) can be written as

$$
1-F(X)=\exp -[f(X)]
$$

or

$$
1-F=\exp -[f(X)]
$$

where $F=F(X)$ and $(1-F)=S$, the probability of survival.

If we have $n$ independent components, each with a probability of the event (failure) not occurring being $(1-F)$, the probability of the event not occurring in the combined total of all components can be expressed from Eq. (A2b) as

$$
1-F^{n}=\exp -[n f(X)]
$$

Equation (A3) gives the appropriate mathematical expression for the principle of the weakest link in a chain or, more generally, for the size effect on failures in solids. As an example of the application of Eq. (A3), we assume a chain consisting of several links. Also, we assume that by testing we find the probability of failure $F$ at any load $X$ applied to a "single" link. If we want to find the probability of failure $F_{n}$ of a chain consisting of $n$ links, we must assume that if one link has failed the whole chain fails. In other words, if any single part of a component fails, the whole component has failed. Accordingly, the probability of nonfailure of the chain $\left(1-F_{n}\right)$, is equal to the probability of the simultaneous nonfailure of all the links. Thus,

$$
1-F_{n}=(1-F)^{n}
$$

or

$$
S_{n}=S^{n}
$$

Or, where the probabilities of failure (or survival) of each link are not necessarily equal (i.e., $S_{1} \neq S_{2} \neq S_{3} \neq \ldots$ ), Eq. (A4b) can be expressed as 


$$
S_{n}=S_{1} \cdot S_{2} \cdot S_{3} \cdot \ldots
$$

This is the same as Eq. (2) of the main text.

From Eq. (A3) for a uniform distribution of stresses throughout a volume $V$

$$
F_{1}=1-\exp -[\mathrm{V} f(\sigma)]
$$

or

$$
S=1-F_{1}=\exp -[V f(\sigma)]
$$

Equation (A5b) can be expressed as follows:

$$
\ln \ln \left[\frac{1}{S}\right]=\ln f(\sigma)+\ln V
$$

It follows that if $\ln \ln (1 / S)$ is plotted as an ordinate and $\ln f(\sigma)$ as an abscissa in a system of rectangular coordinates, a variation of volume $V$ of the test specimen will imply only a parallel displacement but no deformation of the distribution function. Weibull ${ }^{4}$ assumed the form

$$
f(\sigma)=\left[\frac{\sigma-\sigma_{u t}}{\sigma_{\beta}}\right]^{m}
$$

and Eq. (A6) becomes

$$
\ln \ln \left[\frac{1}{S}\right]=m \ln \left(\sigma-\sigma_{u}\right)-m \ln \sigma_{\beta}+\ln V
$$

If $\sigma_{u}$, which is the location parameter, is assumed to be zero and $V$ is normalized whereby $\ln V$ is zero, Eq. (A8) can be written as

$$
\ln \ln \left[\frac{1}{S}\right]=m \ln \left[\frac{\sigma}{\sigma_{\beta}}\right]
$$

Equation (A9) is identical to Eq. (1) of the main text.

The form of Eq. (A9) where $\sigma_{u}$ is assumed to be zero is referred to as "two-parameter Weibull." Where $\sigma_{u}$ is not assumed to be zero, the form of the equation is referred to as "three-parameter Weibull." The Weibull slope or modulus $m$, which is also designated by $e$, is the slope or tangent of the line when the equation is plotted on rectangular coordinates. 


\section{APPENDIX B-DERIVATION OF SYSTEM LIFE EQUATION}

G. Lundberg and A. Palmgren ${ }^{12}$ in 1947, using the Weibull equation for rolling-element bearing life analysis, first derived the relationship between individual component lives and system life. The following derivation is based on but is not identical to the Lundberg-Palmgren ${ }^{12}$ analysis.

From Appendix A, Eq. (A9), the Weibull equation can be written as

$$
\ln \ln \left[\frac{1}{S_{\mathrm{sys}}}\right]=m \ln \left[\frac{N}{N_{\beta}}\right]
$$

where $N$ is the number of cycles to failure.

Referring to the sketch of a Weibull plot in Fig. 9, the slope $m$ can be defined as follows:

$$
m=\frac{\ln \ln \left[\frac{1}{S_{\mathrm{sys}}}\right]-\ln \ln \left[\frac{1}{S_{\mathrm{ref}}}\right]}{\ln N-\ln N_{\text {ref }}}
$$

or

$$
\frac{\ln \left[\frac{1}{S_{\text {sys }}}\right]}{\ln \left[\frac{1}{S_{\text {ref }}}\right]}=\left[\frac{N}{N_{\text {ref }}}\right]^{m}
$$

From Eqs. (B1) and (B2b)

$$
\ln \left[\frac{1}{S_{\text {sys }}}\right]=\left[\ln \frac{1}{S_{\text {ref }}}\right]\left[\frac{N}{N_{\text {ref }}}\right]^{m}=\left[\frac{N}{N_{\beta}}\right]^{m}
$$

and

$$
S=\exp -\left[\frac{N}{N_{\beta}}\right]^{m}
$$

Referring to Fig. 10, for a given time or life $N$, each component or stressed volume in a system will have a different reliability $S$. From Eq. (A4c) for a series reliability system

$$
S_{\mathrm{sys}}=S_{1} \cdot S_{2} \cdot S_{3} \cdot \ldots
$$


Combining Eqs. (B4) and (B5) gives

$$
\exp -\left[\frac{N}{N_{\beta}}\right]^{m}=\exp -\left[\frac{N}{N_{\beta 1}}\right]^{m}+\exp -\left[\frac{N}{N_{\beta 2}}\right]^{m}+\exp -\left[\frac{N}{N_{\beta 3}}\right]^{m}+\ldots
$$

or

$$
\exp -\left[\frac{N}{N_{\beta}}\right]^{m}=\exp -\left\{\left[\frac{N}{N_{\beta 1}}\right]^{m}+\left[\frac{N}{N_{\beta 2}}\right]^{m}+\left[\frac{N}{N_{\beta 3}}\right]^{m}+\ldots\right\}
$$

It is assumed that the Weibull slope $m$ is the same for all components. From Eq. (B6b)

$$
-\left[\frac{N}{N_{\beta}}\right]^{m}=-\left\{\left[\frac{N}{N_{\beta 1}}\right]^{m}+\left[\frac{N}{N_{\beta 2}}\right]^{m}+\left[\frac{N}{N_{\beta 3}}\right]^{m}+\ldots\right\}
$$

Factoring out $N$ from Eq. (B7a) gives

$$
\left[\frac{1}{N_{\beta}}\right]^{m}=\left[\frac{1}{N_{\beta 1}}\right]^{m}+\left[\frac{1}{N_{\beta 2}}\right]^{m}+\left[\frac{1}{N_{\beta 3}}\right]^{m}+\ldots
$$

From Eq. (B3) the characteristic lives $N_{\beta}, N_{\beta 2}, N_{\beta 3}$, etc., can be replaced with the respective lives $N_{1}, N_{2}, N_{3}$, etc., at $S_{\text {ref }}$ (or the lives of each component that have the same probability of survival $S_{\text {ref }}$ ) as follows:

$$
\left[\ln \frac{1}{S_{\text {ref }}}\right]\left[\frac{1}{N_{\text {ref }}}\right]^{m}=\left[\ln \frac{1}{S_{\text {ref }}}\right]\left[\frac{1}{N_{1}}\right]^{m}+\left[\ln \frac{1}{S_{\text {ref }}}\right]\left[\frac{1}{N_{2}}\right]^{m}+\left[\ln \frac{1}{S_{\text {ref }}}\right]\left[\frac{1}{N_{3}}\right]^{m}+\ldots
$$

where, in general, from Eq. (B3)

$$
\left[\frac{1}{N_{\beta}}\right]^{m}=\left[\ln \frac{1}{S_{\mathrm{ref}}}\right]\left[\frac{1}{N_{\mathrm{ref}}}\right]^{m}
$$

and

$$
\left[\frac{1}{N_{\beta 1}}\right]^{m}=\left[\ln \frac{1}{S_{\text {ref }}}\right]\left[\frac{1}{N_{1}}\right]^{m} \text {, etc. }
$$


Factoring out $\ln \left(1 / S_{\text {ref }}\right)$ from Eq. (B8) gives

$$
\frac{1}{N_{\mathrm{ref}}}=\left\{\left[\frac{1}{N_{1}}\right]^{m}+\left[\frac{1}{N_{2}}\right]^{m}+\left[\frac{1}{N_{3}}\right]^{m}+\ldots\right\}^{1 / m}
$$

or rewriting Eq. (B 10) results in

$$
\left[\frac{1}{N}\right]^{m}=\sum_{i=1}^{m}\left[\frac{1}{N_{i}}\right]^{m}
$$

Substituting $e$ as the symbol for the Weibull slope $m$ in Eq. (B11) gives Eq. (9) of the main text. 


\section{REFERENCES}

1. Coy, J.J., "System Life and Reliability," Tribology for Aerospace Applications, E.V. Zaretsky, ed., STLE SP-37, Society of Tribologists and Lubrications Engineers, Park Ridge, IL, 1997, pp. 683-734.

2. Palmgren, A., "The Service Life of Ball Bearings," Zectsckrift des Vereines Deutscher Ingenieure, Vol. 68, No. 14, 1924, pp. 339-341.

3. Zaretsky, E.V., "A. Palmgren Revisited-A Basis for Bearing Life Prediction," Lubrication Engineering, J. STLE, Vol. 54, No. 2, Feb. 1998, pp. 18-24.

4. Weibull, W., "A Statistical Theory of the Strength of Materials," Ingeniors Vetanskaps Akademien-Handlinger, No. 151, 1939.

5. Weibull, W., "The Phenomenon of Rupture in Solids," Ingeniors Vetanskaps AkademienHandlinger, No. 153, 1939.

6. Weibull, W., "A Statistical Distribution Function of Wide Applicability," Trans. ASME, J. Applied Mechanics, Vol. 18, No. 3, 1951, pp. 293-297.

7. Weibull, W., "Efficient Methods for Estimating Fatigue Life Distribution of Rolling Bearings," Rolling Contact Phenomena, J.B. Bidwell, ed., Elsevier, New York, pp. 252-265.

8. Johnson, L.G., The Statistical Treatment of Fatigue Experiments, Elsevier, New York, 1964.

9. Carter, T.L., "Preliminary Studies of Rolling-Contact Fatigue Life of High-Temperature Bearing Materials," NACA RM E57K 12, 1958.

10. Zaretsky, E.V., Anderson, W.J. and Parker, R.J., "The Effect of Contact Angle on RollingContact Fatigue and Bearing Load Capacity," ASLE Trans., Vol. 5, 1962, pp. 210-219.

11. Grisaffe, S.L., "Analysis of Shear Bond Strength of Plasma-Sprayed Alumina Coatings on Stainless Steel, NASA TND-3113, 1965.

12. Lundberg, G., and Palmgren, A., "Dynamic Capacity of Rolling Bearings," Acta Polytechnica, Mechanical Engineering Series, Vol. 1, No. 3, Stockholm, 1947.

13. Anon., "Load Ratings and Fatigue Life for Ball Bearings," ANSI/AFBMA Std. 9-1990, The Anti-Friction Bearing Manufacturers Association, Washington, DC, 1990.

14. Anon., "Load Rating and Fatigue Life for Roller Bearings," ANSI/AFBMA Std. 11-1990, The Anti-Friction Bearing Manufacturers Association, Washington, DC, 1990.

15. Anon., "Rolling Bearings. Dynamic Load Ratings and Rating Life," ISO 28l-1990(E), International Organization for Standardization, 1990.

16. Zaretsky, E.V., "Design for Life, Plan for Death," Machine Design, Vol. 66, No. 15, 1994, pp. 55-59.

17. Zaretsky, E.V., "Fatigue Criterion to System Design, Life and Reliability," Trans. AIAA, J. Propulsion and Power, Vol. 3, No. 1, 1987, pp. 76-83.

18. Ioannides, E., and Harris, T.A., "A New Fatigue Life Model for Rolling Bearing," Trans. ASME, J. Tribology, Vol. 107, No. 3, 1985, pp. 367-378.

19. August, R., and Zaretsky, E.V., "Incorporating Finite Element Analysis Into Component Life and Reliability," Trans. ASME, J. Mechanical Design, Vol. 115, No. 4, 1993, pp. 706-710.

20. Holland, F.A., Jr., Zaretsky, E.V., and Melis, M.E., "Probabilistic Failure Prediction of SCS-6/Ti-15-3 MMC Ring, Trans. ASME, J. Mechnical Design, Vol. 120, No. 4, 1998, pp. 714-720.

21. Melis, M.E., and Ogonek, J.A., "A Life Prediction Algorithm Implemented in P3 Using PCL," Paper 19, Proceedings of MSC World Users Conference, MacNeal-Schwendler, Los Angeles, 1995. 
22. Mahorter, R., London, G., Fowler, S., and Salvino J., "Life Prediction Methodology for Aircraft Gas Turbine Engine Disks," Proceedings of AIAA, SAE, ASME, ASEE 21 st Joint Propulsion Conference, Monterey, CA, July 8-10, 1985. (AIAA Paper 85-1141, 1985.)

23. Zaretsky, E.V., Smith, T.E., and August R., "Effect of Design Variables, Temperature Gradients and Speed on Life and Reliability of a Rotating Disk," Trans. ASME, J. Vibration, Acoustics, Stress and Reliability in Design, Vol. 111, No. 3, 1989, pp. 311-317.

24. Anon., Aerospace Structural Materials Handbook, W.F. Brown, Jr., H. Mindlin, and C.Y. Ho, eds., CINDAS/USAF CRDA Handbooks Operation, Purdue University, West Lafayette, IN, 1997.

25. Langer, B.F., "Fatigue Failure From Stress Cycles of Varying Amplitude," Trans. ASME, J. Applied Mechanics, Vol. 59, 1937, pp. A160-A162.

26. Miner, M.A., "Cumulative Damage in Fatigue," Trans. ASME, J. Applied Mechanics, Vol. 12, No. 3, 1945, pp. A159-A164.

TABLE 1 - - TURBINE DISK MATERIAL PARAMETERS

\begin{tabular}{|l|l|}
\hline Material & Titanium (Ti-6Al-4V) alloy \\
Elastic modulus GPa (ksi) & $11.0\left(16 \times 10^{3}\right)$ \\
Poisson's ratio & 0.33 \\
Weibull slope & 2 \\
Density kg/m ${ }^{3}\left(\mathrm{lb} / \mathrm{in}^{3}{ }^{3}\right)$ & $4429(0.16)$ \\
Stress-life exponent & 9.2 \\
$\tau_{+4}$ fatigue limit. MPa $(\mathrm{ksi})$ & $258.5(37.5)$ \\
\hline
\end{tabular}

TABLE 2.-SUMMARY OF LOW-CYCLE-FATIGUE ENDURANCE DATA FOR GAS TURBINE ENGINE COMPRESSOR DISKS SUBJECTED TO BOTH ENGINE OPERATION AND SPIN PIT TESTS

[Material. titanium (Ti-6Al-4V) alloy: speed. $11200 \mathrm{rpm}$.]

\begin{tabular}{|c|c|c|c|c|c|c|c|c|}
\hline \multirow[t]{2}{*}{$\begin{array}{l}\text { Test } \\
\text { disk }\end{array}$} & \multicolumn{3}{|c|}{ Operating time, cycles" } & \multirow[t]{2}{*}{ Comments $^{h}$} & \multicolumn{3}{|c|}{$\begin{array}{c}\text { Experimental life, } \\
\text { cycles: }\end{array}$} & \multirow{2}{*}{$\begin{array}{l}\text { Weibull } \\
\text { slope. } \\
e\end{array}$} \\
\hline & $\begin{array}{c}\text { Loaded } \\
\text { (engine } \\
\text { operation) }\end{array}$ & $\begin{array}{l}\text { Unloaded } \\
\text { (spin pit } \\
\text { tests) }\end{array}$ & Total & & $L_{n 11}$ & $L_{\mathrm{HH}}$ & $L_{\$ 1}$ & \\
\hline \multicolumn{9}{|c|}{ Disks A (Fig. I(a)) } \\
\hline Al & 1966 & 7100 & 9066 & Failed & 594 & 7900 & $2190(0)$ & 1.8 \\
\hline A2 & 2932 & 11100 & 14032 & Failed & & & & \\
\hline A3 & 2779 & 17100 & 19879 & Failed & & & & \\
\hline A4 & 37.50 & 21000 & 24750 & Unfailed & & & & \\
\hline A5 & 2947 & 33100 & 36047 & Failed & $\nabla$ & $\nabla$ & $\nabla$ & + \\
\hline \multicolumn{9}{|c|}{ Disks B (Fig. 1(b)) } \\
\hline $\mathrm{Bl}$ & 3437 & 12100 & 155.37 & Failed & 58.32 & $13600)$ & 19200 & 5.5 \\
\hline $\mathrm{B} 2$ & 2616 & 13100 & 15716 & Failed & & & & \\
\hline B3 & 3149 & 16100 & 19249 & Failed & & & & \\
\hline B4 & 2880 & 21000 & 23880 & Unfailed & & & & \\
\hline B5 & 2755 & $300(0)$ & 32885 & Unfailed & & & & \\
\hline
\end{tabular}

"Data from Ref. 22

"All failures were bolt hole cracks exceeding $0.7938 \mathrm{~mm}(0.03125 \mathrm{in.}$ ) ( ref. 22).

'See Fig. 3 for Weibull plot of data. 
TABLE 3.-NORMALI/ED PREIICICTED $L_{11}$ LIVES OF GAS TURBINE ENGINE: COMPRESSOR DISKS AS FUNCTION LOAD

[Matcrial, titanium (Ti-6Al-4V) alloy; reference stress. $\tau_{+4} .509 .2 \mathrm{MPa}(73.846 \mathrm{ksi})$ : reference volume. $V_{n: 3}, 2.264709 \times 10^{-111} \mathrm{~m}^{3}\left(1.3820105 \times 10^{-5}\right.$ in. $\left.{ }^{3}\right)$ : reference life.

$l_{\text {II. }} 1$ cycle (nomalized): disk speed. $11200 \mathrm{rpm}$ : stress-life exponent. 9.2:

Weibull slope. 2: $\tau_{+4}$. fatigue limit. $258.6 \mathrm{MPa}(37.5 \mathrm{ksi})$.

\begin{tabular}{|c|c|c|c|c|}
\hline \multirow[t]{5}{*}{ Parameter } & \multicolumn{4}{|c|}{ Predicled normalized $L_{11}$ life. cycles } \\
\hline & \multicolumn{2}{|c|}{ Disks A (Fig. l(a)) } & \multicolumn{2}{|c|}{ Disks B (Fig I(h)) } \\
\hline & Unloaded & Loaded & Unloaded & Loaded \\
\hline & \multicolumn{4}{|c|}{ Segment angle, deg } \\
\hline & \multicolumn{2}{|c|}{60} & \multicolumn{2}{|c|}{30} \\
\hline $\begin{array}{l}\text { Segment life } \\
\text { Disk life } \\
\text { Time at loud nercent }\end{array}$ & $\begin{array}{r}26,30.9 \\
1074.1 \\
82\end{array}$ & $\begin{array}{r}0.14618 \\
0.05968 \\
18\end{array}$ & $\begin{array}{r}75.118 \\
21.7(149 \\
85\end{array}$ & $\begin{array}{r}0.15307 \\
0.04419 \\
15\end{array}$ \\
\hline Combined load-cycle disk life & \multicolumn{2}{|c|}{0.33147} & \multicolumn{2}{|c|}{0.29123} \\
\hline \multicolumn{5}{|c|}{ (b) Faligue limit } \\
\hline $\begin{array}{l}\text { Segment life } \\
\text { Disk life } \\
\text { Time at load. percent }\end{array}$ & $\begin{array}{r}8171.2 \\
3335.8 \\
82\end{array}$ & $\begin{array}{r}0.14673 \\
0.05990 \\
18\end{array}$ & $\begin{array}{r}7692.5 \\
222(1.6 \\
8.5\end{array}$ & $\begin{array}{r}0.15324 \\
0.04424 \\
15\end{array}$ \\
\hline Combined load-cycle disk life & \multicolumn{2}{|c|}{0.33275} & \multicolumn{2}{|c|}{0.29490} \\
\hline
\end{tabular}

TABLE 4-PREDICTEI) $l_{11}$ LIVES OF GAS TURBINH ENGINE COMPRESSOR DISKS FOR ENGINE LOADS AS FUNCTION OF SPEFI) [Material, titanium (Ti-6Al-4V) alloy: reference stress, $\tau_{+4} .5(1) .2 \mathrm{MPa}$ $(73.846 \mathrm{ksi})$; reference volume. $V_{n+1} .2 .264709 \times 10^{-111} \mathrm{~m}^{7}\left(1.38201015 \times 10^{-5}\right.$ in. $\left.{ }^{3}\right)$; stress-life exponenı. 9.2: Weibull slope. 2; fatigue limit. none assumed.]

\begin{tabular}{|c|c|c|c|c|}
\hline \multirow[t]{3}{*}{ Speed. rpm } & \multicolumn{4}{|c|}{ Predicted $L_{1 ; 1}$ life } \\
\hline & \multicolumn{2}{|c|}{ Disks A } & \multicolumn{2}{|c|}{ Disks B } \\
\hline & Cycles & $\mathrm{Hr}$ & Cycles & $\mathrm{Hr}$ \\
\hline 3730 & 3862 & $56(0)$ & 24153 & 37186 \\
\hline 74.59 & 963 & 1396 & 2133 & 328.5 \\
\hline 11200 & 139 & 202 & 103 & 159 \\
\hline 14930 & 16 & 23 & 5 & 8 \\
\hline \multicolumn{5}{|c|}{ (b) $L_{\mathrm{rrt}}=1.32 .37 .3 \mathrm{cycles}$} \\
\hline 3730 & 21450 & 31103 & 134150 & 206.593 \\
\hline 7459 & 5349 & 7754 & 11847 & 18245 \\
\hline $112(x)$ & 774 & 1122 & 572 & 883 \\
\hline 14930 & 89 & 128 & 28 & 44 \\
\hline
\end{tabular}

TABLE 5.-SUMMARY AND COMPARISON OF DISK $L_{11}$ LIFE PREDICTIONS WITH EXPERIMENTAL $L$ LIVES

[Material. titanium (Ti-6Al-4V) alloy: speed. $11200 \mathrm{rpm}$.]

\begin{tabular}{|c|c|c|c|c|c|c|c|c|}
\hline \multirow{3}{*}{$\begin{array}{c}\text { Dish } \\
\text { designation }\end{array}$} & \multicolumn{8}{|c|}{ Disk $L_{1,1}$ life } \\
\hline & \multicolumn{2}{|c|}{$\begin{array}{l}\text { NAPC crack growth } \\
\text { method (from kef. 22) }\end{array}$} & \multicolumn{2}{|c|}{$\begin{array}{l}\text { Modified crack growth } \\
\text { method (F., }(20))\end{array}$} & \multicolumn{2}{|c|}{$\begin{array}{l}\text { 7aretsky probable cause } \\
\text { method (from Table } 4(b))\end{array}$} & \multicolumn{2}{|c|}{$\begin{array}{l}\text { Experimental } \\
\text { (from Table 2) }\end{array}$} \\
\hline & Cycles & $\overline{\mathrm{Hr}}$ & Cycles & $\mathrm{Hr}$ & Cycles & $\mathrm{Hr}$ & Cycles & $\mathrm{Hr}$ \\
\hline $\bar{A}$ & 2138 & 3100 & 617 & 895 & 774 & 1122 & 594 & 861 \\
\hline B & 1655 & $24(0)$ & 478 & 693 & 572 & 88.3 & 5832 & 8981 \\
\hline
\end{tabular}




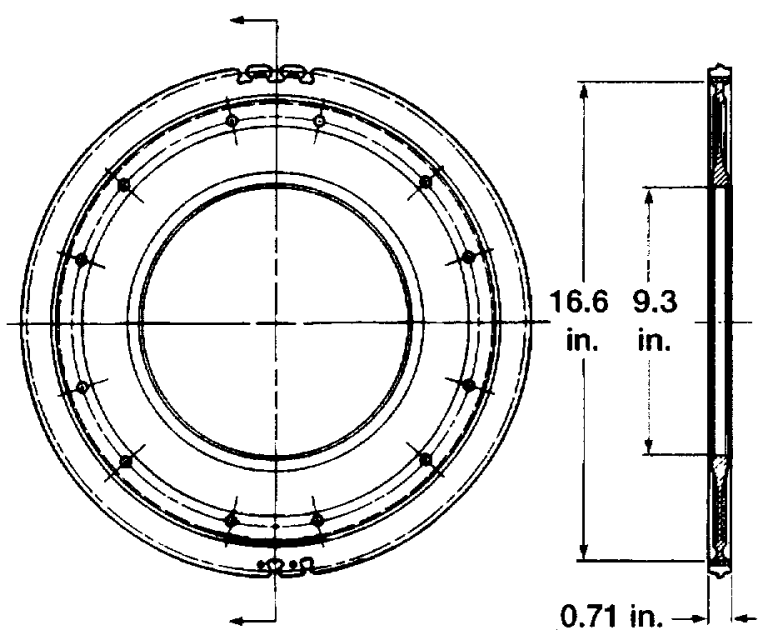

(a) Disk A.

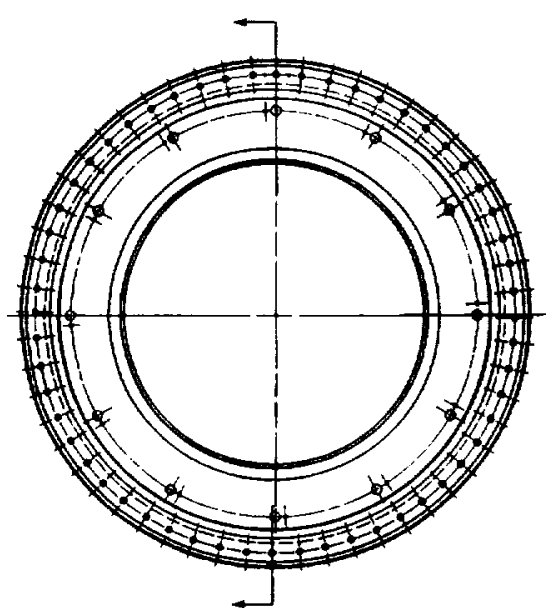

(b) Disk B.

Figure 1.-Schematic of compressor disks used for analysis and testing. Material, titanium (Ti-6Al-4V) alloy.

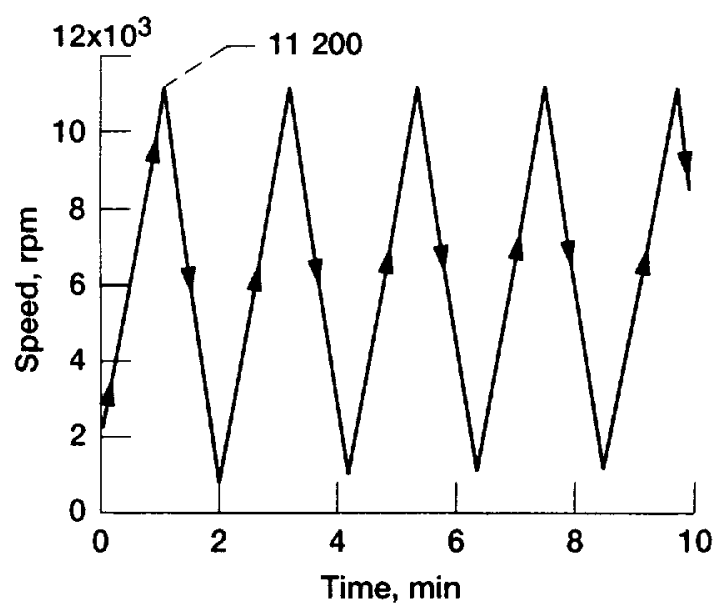

Figure 2.-Spin pit test cycle speed for compressor disks as function of time. (From ref. 22.)

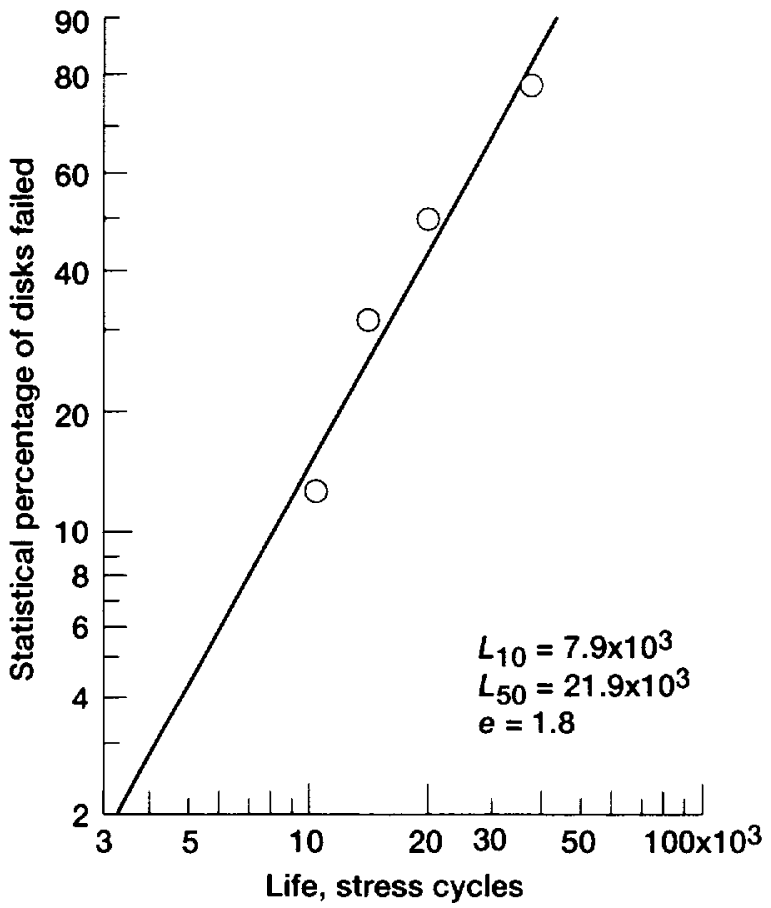

(a) Disks A.

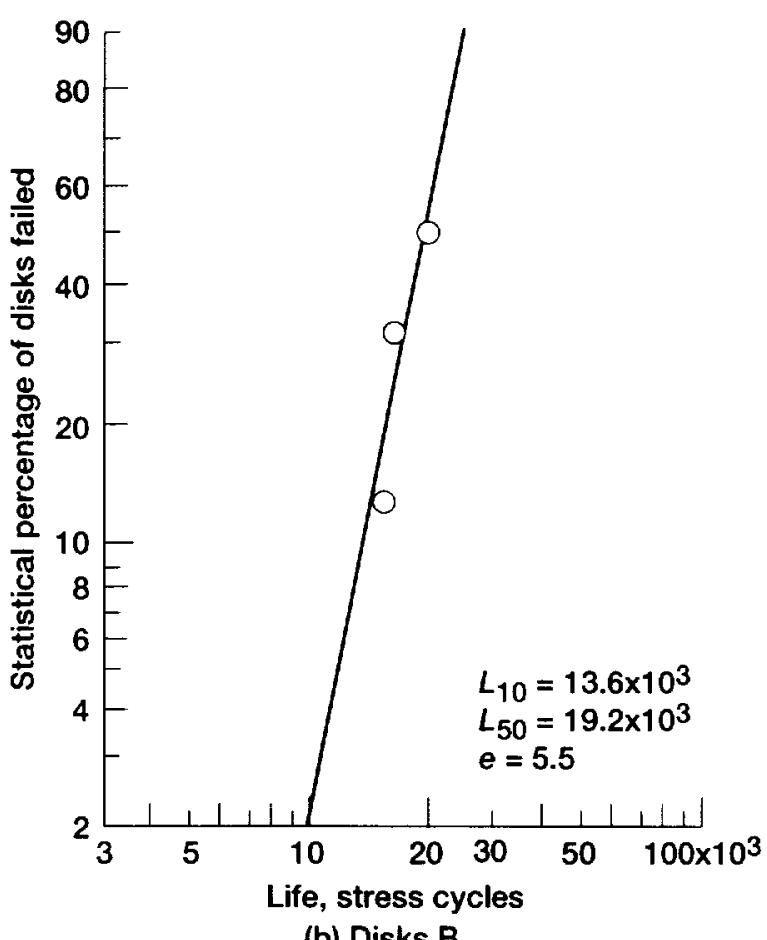

Figure 3.-Weibull analysis of low-cycle-fatigue testing of combined rim-loaded and unloaded turbine disks. Speed, $11200 \mathrm{rpm}$. (Data from ref. 22.) 


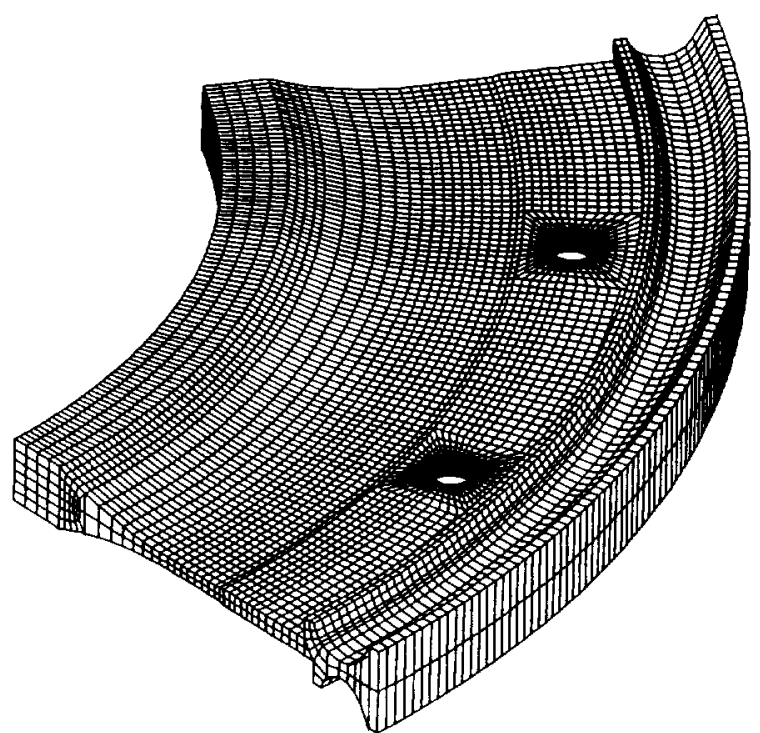

(a) Disk $A, 60^{\circ}$ segment.

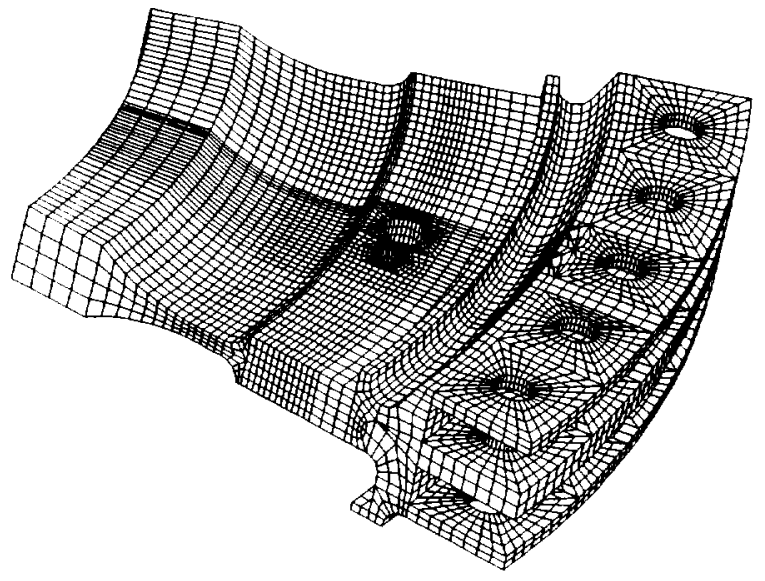

(b) Disk B, $30^{\circ}$ segment.

Figure 4.-Mesh layout of turbine disks for finite-element analysis.

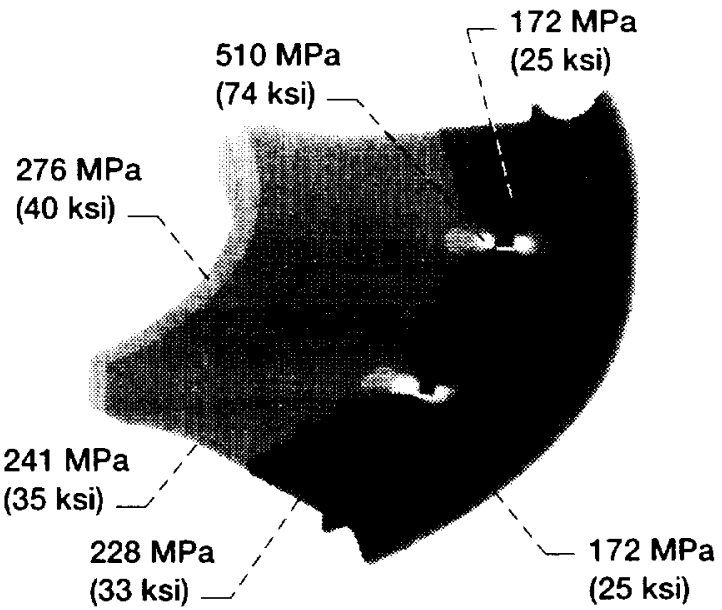

(a) Disk $A, 60^{\circ}$ segment.

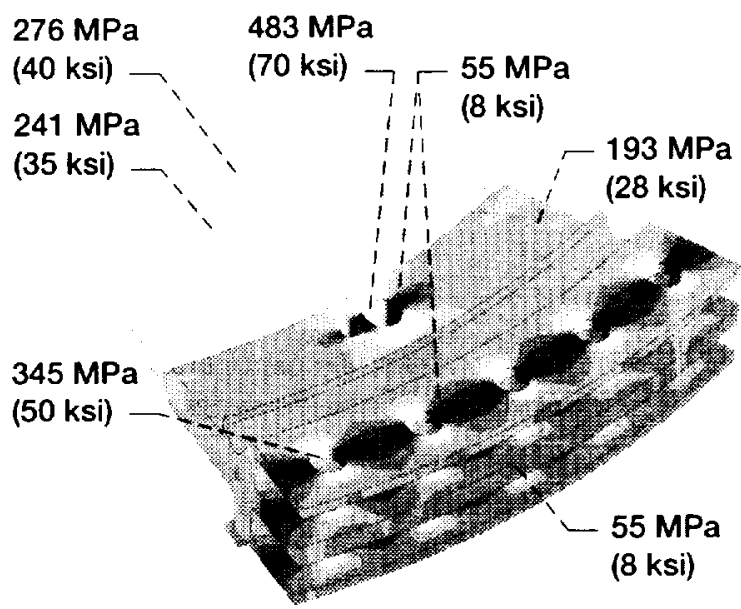

(b) Disk $B, 30^{\circ}$ segment.

Figure 5.-Maximum shear stress profiles for rimloaded compressor disks based on finite-element analysis. Speed, $11200 \mathrm{rpm}$. 


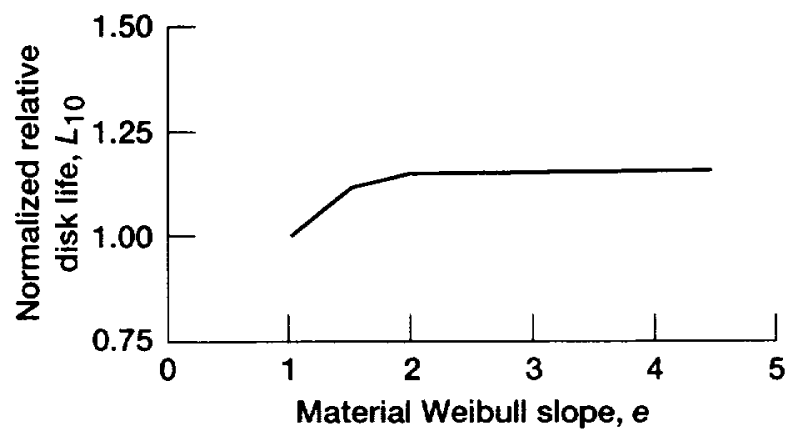

(a) Effect of Weibull slope.

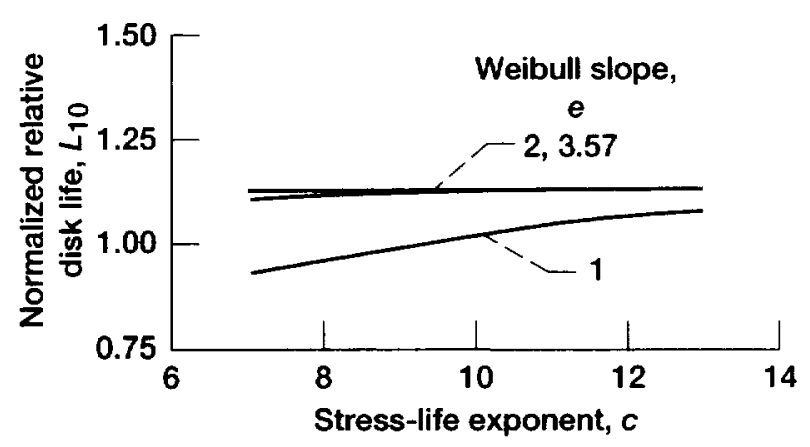

(b) Effect of stress-life exponent.

Figure 6.-Effect of Weibull slope and stress-life exponent on predicted $L_{10}$ life of generic rotating disk. (From ref. 23.)

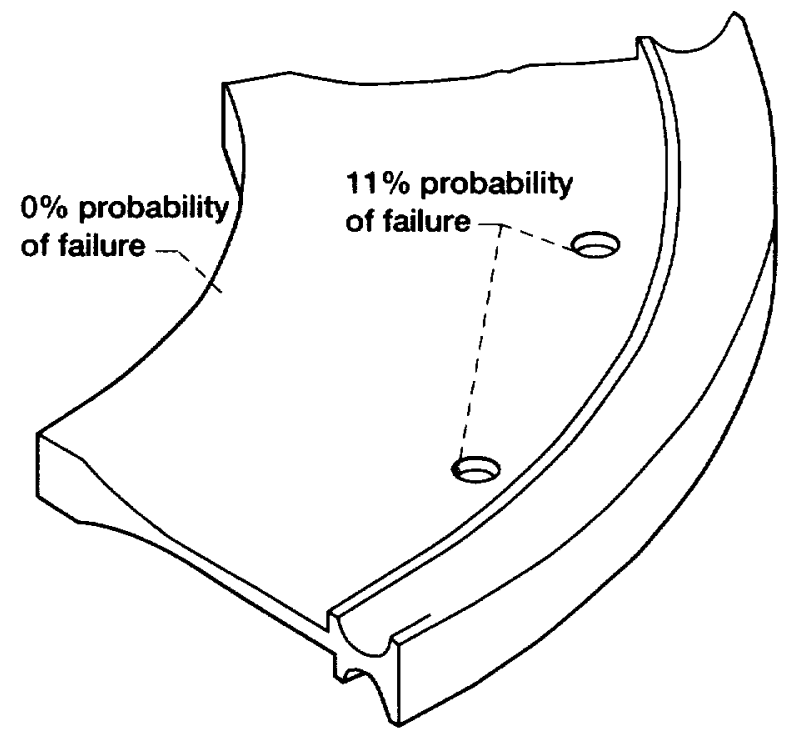

(a) Disk $A, 60^{\circ}$ segment.

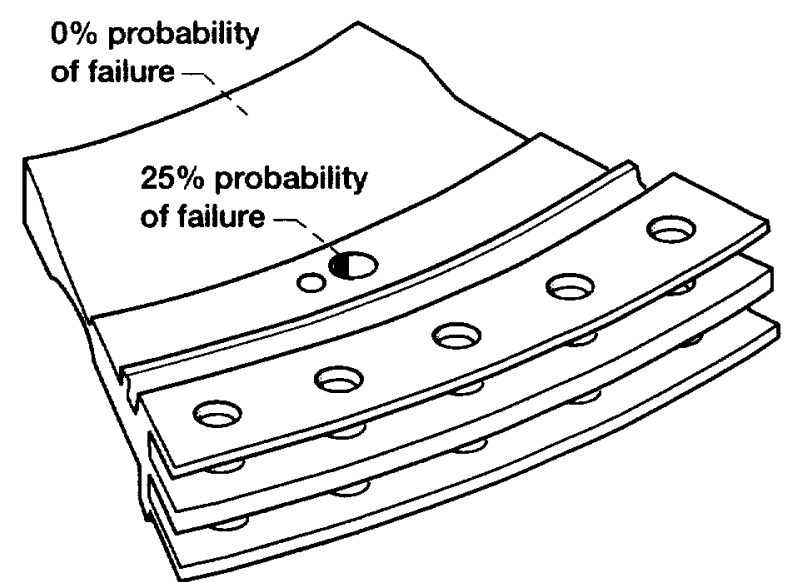

(b) Disk B, $30^{\circ}$ segment.

Figure 7.-Normalized probability of failure based on Probable Cause analysis of rim-loaded compressor disks. Speed, $11200 \mathrm{rpm}$. 


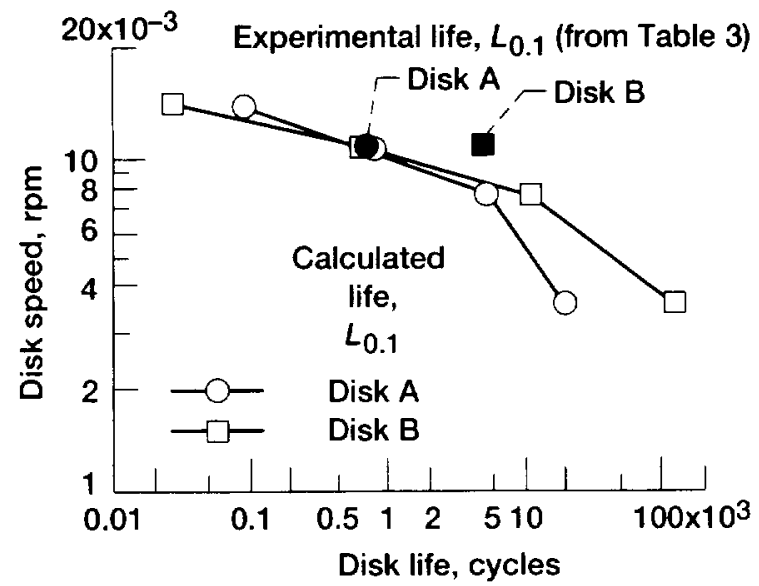

Figure 8.-Calculated $L_{0.1}$ lives of gas turbine engine compressor disks as function of speed under engine load. Material, titanium (Ti-6Al-4V) alloy; reference life, $L_{\text {ref }}, 132373$ cycles; reference stress, $\tau_{45}, 509.2 \mathrm{MPa}(73.846 \mathrm{ksi}) ;$ reference volume, $V_{\text {ref }}$, $2.264709 \times 10^{-10} \mathrm{~m}^{3}\left(1.3820105 \times 10^{-5}\right.$ in. $\left.^{3}\right)$; stress-life exponent, $c, 9.2$; Weibull slope, e, 2; fatigue limit, none assumed.

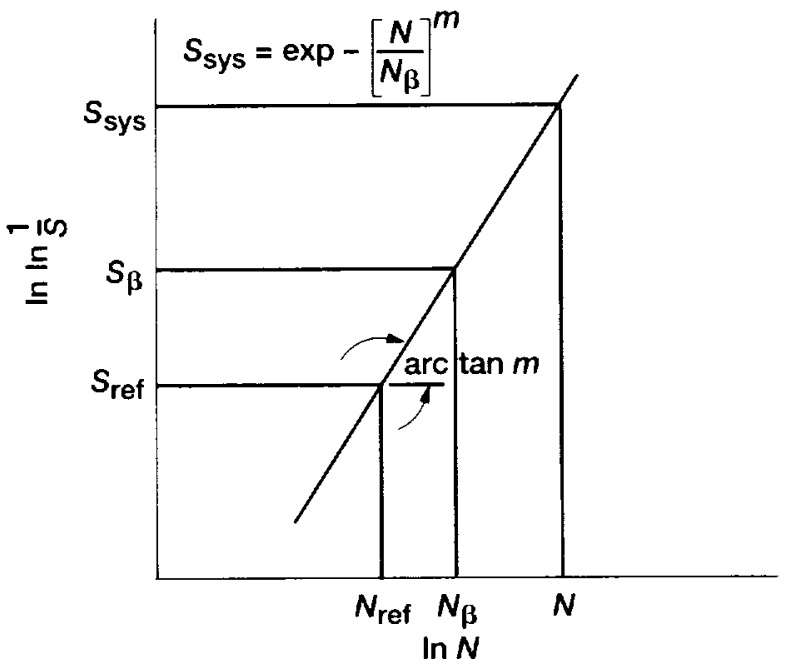

Figure 9.-Sketch of Weibull plot where (Weibull) slope or tangent of line is $m$. $S_{\beta}$ is probability of survival of 36.8 percent at which $N=N_{\beta}$ or $N / N_{\beta}=1$.

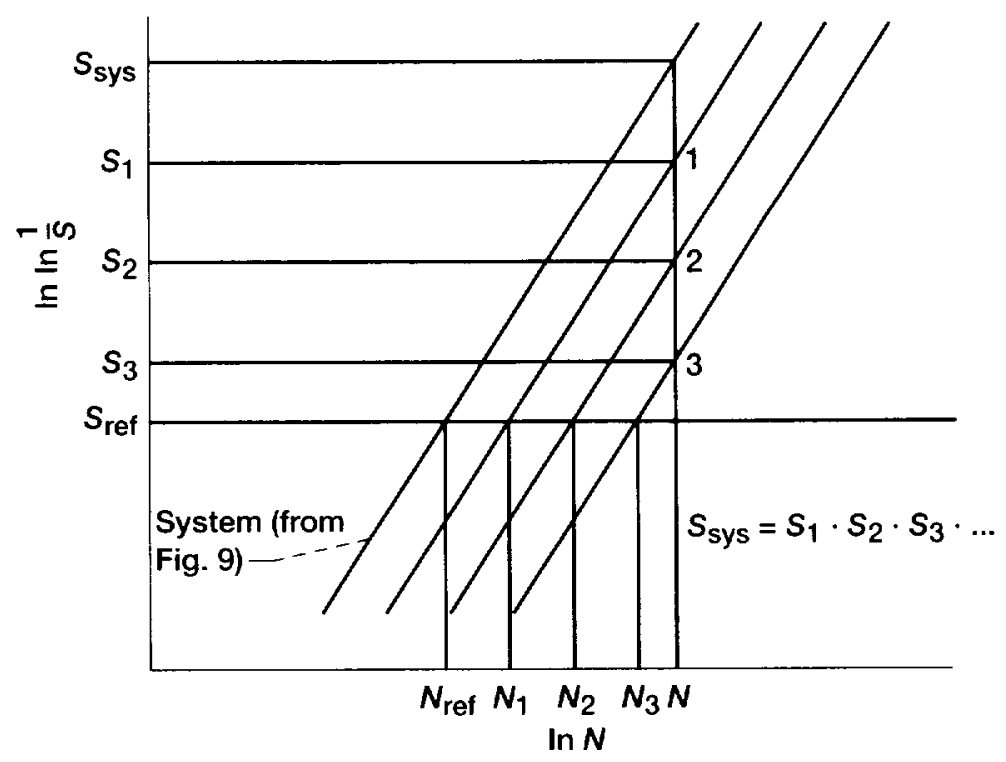

Figure 10.-Sketch of multiple Weibull plots where each numbered plot represents cumulative distribution of each component in system and system Weibull plot represents combined distribution of plots $1,2,3$, etc. (All plots are assumed to have same Weibull slope $\mathrm{m}$.) 
Probabilistic Analysis of Aircraft Gas Turbine Disk Life and Reliability

6. AUTHOR(S)

WU $-523-22-1.3-00$

Matthew E. Melis, Erwin V. Zaretsky, and Richard Augusı

7. PERFORMING ORGANIZATION NAME(S) AND ADDRESS(ES)

National Aeronautics and Space Administration

John H. Glenn Research Center at Lewis Field

Cleveland, Ohio 441.35-3191

8. PEFFORMING ORGANIZATION

REPORT NUMBER

E-10629-2

9. SPONSORING/MONITORING AGENCY NAME(S) AND ADDRESS(ES)

National Aeronautics and Space Administration

Washington, DC 20546-0001

10. SPONSORING/MONITORING AGENCY REPORT NUMBER

NASA TM-1999-107436

\section{SUPPLEMENTARY NOTES}

Matthew E. Melis and Erwin V. Zaretsky, NASA Glenn Research Center: Richard August, NYMA, Inc., 2001 Aerospace Park way, Brook Park, Ohio (work partially funded by NASA Contract NAS3-27186. Currently with NYMA. Incorporated, 9 North Wright Street, Langley Research Center, Hampton, Virginia 23681). Responsible person, Matthew E. Melis, organization code 5930, (216) 433-3322.

\begin{tabular}{|l|l|}
\hline 12a. DISTRIBUTIONAVAILABILITY STATEMENT & 12b. DISTRIBUTION CODE
\end{tabular}

Unclassified - Unlimited

Subject Category: 37

Distribution: Nonstandard

This publication is available from the NASA Center for AeroSpace Information. (301) 621-0390.

13. ABSTRACT (Maximum 200 words)

Two series of low cycle fatigue (LCF) test data for two groups of different aircraft gas turbine engine compressor disk geometries were reanalyzed and compared using Weibull statistics. Both groups of disks were manufactured from titanium (Ti-6Al-4V) alloy. A NASA Glenn Research Center developed probabilistic computer code "Probable Cause" was used to predict disk life and reliability. A material-life factor "A" was determined for titanium (Ti-6Al-4V) alloy based upon fatigue disk data and successfully applied to predict the life of the disks as a function of speed. A comparison was made with the currently used life prediction method based upon crack growth rate. The application of an endurance limit to the computer code did not significantly affect the predicted lives under engine operating conditions. Failure location prediction correlates with those experimentally observed in the LCF tests. A reasonable correlation was obtained between the predicted disk lives using the Probable Cause code and a modified crack growth method for life prediction. Both methods slightly overpredict life for one disk group and significantly under predict it for the other.

\section{SUBJECT TERMS}

Probability theory; Fatigue life; Life (durability); Rotating disks; Crack initiation; Structural design; Structural reliability

\begin{tabular}{|l|} 
15. NUMBER OF PAGES \\
31 \\
\hline $\begin{array}{c}\text { 16. PRICE CODE } \\
\text { AOS } 3\end{array}$ \\
20. LIMITATION OF ABSTRACT
\end{tabular}




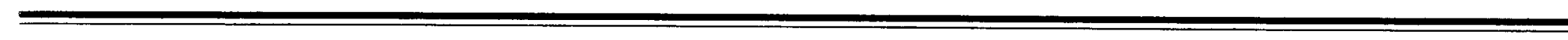

